\title{
Gene Product Sequence Variation
}

National Cancer Institute

\section{Source}

National Cancer Institute. Gene Product Sequence Variation. NCI Thesaurus. Code C97928.

A variation in the amino acid sequence of a specific gene product. 